\title{
Externalidades ambientales ocasionadas por la urbanización en la ciudad de Medellín
}

\author{
Environmental externalities caused by urbanization in the city of Medellín
}

Olgalicia Palmett Plata, ${ }^{1}$ M.Sc.

${ }^{1}$ Institución Universitaria Colegio Mayor de Antioquia. Medellín, Antioquia. Magister en Diseño del Paisaje. Correspondencia: olgalicia.palmett@colmayor.edu.co

Recibido: 30 de marzo de 2016. Aceptado: 19 de mayo de 2016.

Palmett, O. (2016) Externalidades ambientales ocasionadas por la urbanización en la ciudad de Medellín. Procesos urbanos Número 3, Ene-Dic. 38-54. Doi:10.21892/2422085X.266

\section{RESUMEN}

Este trabajo tiene como objetivo realizar una reflexión sobre la forma cómo, en la ciudad de Medellín, se han enfrentado las externalidades ambientales, ocasionadas por las dinámicas de urbanización, en las décadas entre 1990 y 2010 . Se busca como resultado conocer y aportar las nuevas acciones de mejoramiento implementadas en Medellín, para contrarrestar las externalidades ambientales ocasionadas por la urbanización, a la luz del aprovechamiento de características propias de un contexto, como son, en el caso de la ciudad de Medellín, una ubicación geográfica estratégica, relieve singular, conflictos sociales de conocida particularidad, tradiciones culturales arraigadas y posibilidades económicas reducidas, entre otras. Además, se pretende revelar y potenciar las articulaciones que estratégicamente se han ido constituyendo en las políticas de gestión ambiental urbana y los logros obtenidos ante los principios fundamentales $(1,8$ y 26$)$ de la Cumbre de Río de Janeiro (1992), ante las externalidades ambientales en la ciudad y que pueden ser asumidos como modelo de actuación para territorios con comportamientos similares.

Palabras clave: Ciudad, externalidades ambientales, urbanización, afectaciones.

\section{ABSTRACT}

This paper aims to reflect on how, in the city of Medellín, environmental externalities, caused by the dynamics of urbanization, have been faced in the decades between 1990 and 2010. As a result, we seek to know and contribute to the new improvement actions implemented in Medellín, to counteract the environmental externalities caused by urbanization, by using the proper characteristics of a particular context, such as, in the case of the city of Medellín, a strategic geographical location, a singular relief, social conflicts of a known particularity, entrenched cultural traditions and reduced economic possibilities, among others. In addition, it seeks to reveal and strengthen the articulations that have been strategically established in urban environmental management policies and the achievements in view of the fundamental principles $(1,8$ and 26) of the Rio de Janeiro Summit (1992), before the environmental externalities in the city and that can be assumed as a model of action for territories with similar behaviors.

Keywords: City, environmental externalities, urbanization, affectations. 
Palmett, O. - Externalidades ambientales ocasionadas por la urbanización.

\section{INTRODUCCIÓN}

El crecimiento urbano en Medellín se ha caracterizado por una expansión física de la ciudad, ocurrida en forma casi incontrolada que ha tenido profundas repercusiones en el ambiente y su sustentabilidad, cómo se puede comprobar en los registros detallados y estadísticos del documento técnico de soporte POT (Acuerdo 046 de 2006). (Alcaldía de Medellín, p.84).

Con este trabajo se ha realizado un análisis de los efectos ambientales negativos del crecimiento urbano de la ciudad de Medellín, con énfasis en las implicaciones ambientales pasadas, actuales y futuras.

La reflexión sobre la forma como la ciudad de Medellín ha enfrentado las externalidades ambientales, ocasionadas por las dinámicas de urbanización en las décadas entre 1990 y 2010, implica necesariamente marcarse unos objetivos específicos como son:

- Indagar sobre las externalidades ambientales negativas presentadas en la ciudad de Medellín entre los años 1990 y 2010, a partir de las actividades de urbanización.

- Revisar los planes, estrategias o acciones aplicadas para contrarrestar las externalidades ambientales negativas ocurridas en la ciudad de Medellín, producto de las dinámicas de urbanización, en estas dos últimas décadas.

- Analizar los resultados obtenidos de las intervenciones realizadas a las externalidades ambientales ocurridas en la ciudad de Medellín, producto de las dinámicas de urbanización, en estas dos últimas décadas, desde el punto de vista de los ecosistemas, los recursos naturales, los riesgos ambientales y la escasez ecológica.

Para llevar a cabo este trabajo se acude a la función específica de las metodologías de la economía ambiental, mediante la cual se conoce la estimación de los daños ambientales de la relación de equilibrios y desequilibrios existentes entre la conservación de los recursos naturales y ambientales de la ciudad y las actividades económicas necesarias para su impulso y crecimiento económico, con miras a la maximización del bienestar económico y social.

Para la recolección de información se tuvieron en cuenta aspectos cualitativos y cuantitativos, llevando a cabo técnicas como:

- Pesquisas de documentos territoriales del contexto de estudio de Medellín.

- Análisis de contenidos cartográficos de mapas, planos e imágenes.

- Rastreo bibliográfico

- Contrastación de imágenes de la ciudad, tomadas en distintas épocas.

Las actividades que determinaron el procesamiento y análisis de los datos fueron:

- El establecimiento de categorías precisas, a fin de clasificar los datos, para que se adecuaran al propósito del estudio y permitieran poner de manifiesto las semejanzas y relaciones significativas.

- La generación de instrumentos cartográficos, tablas y gráficos en los que se organizaron los resultados de nuevos análisis y combinaciones.

\section{MARCO CONCEPTUAL}

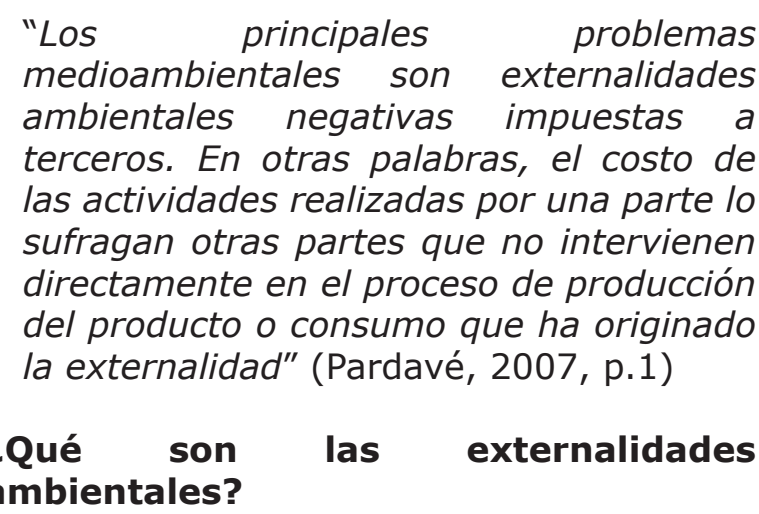

Se entiende por externalidades ambientales a toda consecuencia indirecta y generalmente adversa ocasionada a las personas, producto de transacciones de mercado, es decir, los efectos causados a personas que no pertenecen a la relación del mercado en la transacción actual. Estas externalidades se producen siempre que una persona o

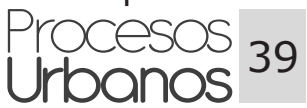


empresa, realice una actividad que afecta el bienestar de otras personas o empresas que no están participando en la transacción, y cuya afección no repercute en compensación alguna por ello. (Castro \& Mokate, 1998).

Desde la concepción de Stiglitz, (2000) la externalidad es la acción de un agente económico, empresa o persona, que afecta a un tercero, por el que no paga ni es pagado, convirtiéndolo en una falla del mercado. Estas acciones pueden beneficiar o perjudicar a otros, se traducen en externalidades positivas o negativas.

"Una externalidad ocurre siempre que las actividades de un agente económico afecten las actividades de otro agente de una forma que no queda reflejada en las transacciones del mercado". (Nicholson, 2008, p.587)

Una externalidad ambiental es calificada como un costo que no refleja su precio real en el mercado, es decir, que escapa de la transacción propia del mercado en sí, en donde el medio ambiente o las personas salen perjudicadas. Dicho en palabras de Rocha, Pinzón y Usaquén:

"En el escenario neoclásico, los únicos costos en la actividad económica son los costos de producción, no existe ningún costo asociado al intercambio. En este marco las fallas del mercado son situaciones ineficientes, en el sentido que la economía no alcanza el nivel de bienestar teóricamente posible, además de que no imponen ningún costo real a la sociedad". (2007, p. 168).

Esto ocurre por la simple razón que los activos ambientales no son mercadeables, no existe un mercado para ellos, por lo tanto, no existen derechos de propiedad definidos. Y como si fuera poco lo anterior, el mercado no genera compensaciones económicas a los afectados por las externalidades.

Autores como Gonzalo Delacámara, del Departamento de Fundamentos de Economía e Historia Económica de la Universidad de Alcalá, España, bajo la supervisión de Carlos de Miguel, de la Comisión Económica para América Latina (CEPAL), ha investigado sobre la conveniencia o no de adoptar decisiones más complejas y, por lo tanto, mejores, sobre estas externalidades, las cuales deberían ser debidamente cuantificadas e incorporadas en el marco de un análisis coste-beneficio de las decisiones públicas o privadas de la sociedad.

"Analizar los costes externos de diferentes actividades económicas (industria, agricultura, provisión de agua potable, transporte, conversión de energía, etc.) es relevante, entre otras cosas, por una sencilla razón: el mercado tiende a generar demasiada actividad en sectores económicos donde las externalidades existen. Para contrarrestar esta tendencia (que no se refleja en la valoración de bienes relativos a través de los precios de mercado), o mitigar sus impactos, es precisa la intervención del sector público." (Delacámara, 2008, p.13).

Otro autor que al respecto ha aportado es Gary Stanley Becker, economista estadounidense y profesor de la Universidad de Chicago, quien recibió el Premio Nobel de Economía en 1992 por ampliar el dominio del análisis microeconómico a un mayor rango de comportamientos humanos fuera del mercado. Economista en defensa del ser humano, quien crea el modelo simple de crimen racional, en el que las personas al sopesar costes y beneficios, no dejan margen a plantearse sobre lo correcto y lo incorrecto, basándose en un análisis costo-beneficio ante las externalidades ambientales, como bien lo expone Delacámara ante las intervenciones económicas de Becker:

"Eshabitual, porejemplo, quelosimpuestos sobre combustibles estén diseñados para aumentar la recaudación fiscal y no para introducir incentivos o reflejar los daños que la contaminación atmosférica ocasiona sobre la salud humana, las explotaciones agrarias, los activos inmobiliarios de las ciudades o los ecosistemas. Es común, al mismo tiempo, que las decisiones sobre la matriz óptima de generación eléctrica de un país determinen un uso excesivo de fuentes no renovables e intensivas en emisiones contaminantes por entender que la generación de un kWh es menos costosa (aunque el precio del petróleo 
Palmett, O. - Externalidades ambientales ocasionadas por la urbanización.

ayude a matizar esta tendencia). De hecho, es posible que esto sea así, si uno piensa en términos financieros, pero no menos probable que sea absolutamente incierto si se incorporan las externalidades de cada tecnología de generación a lo largo del ciclo de vida de dicho kWh. Algo similar podría afirmarse, por ejemplo, en el caso de las decisiones para priorizar un modo de transporte urbano sobre otro." (Delacámara, 2008, p.6)

Las externalidades ambientales se conocen también con el nombre de economías externas o efectos externos, utilidades externas o efectos de vecindad o efecto derrama. La disciplina encargada de estudiar y evaluar los efectos de las externalidades ambientales es la economía ambiental. Disciplina nacida dentro del ámbito de la economía que trata de aplicar los instrumentos analíticos de la economía convencional, al análisis de las decisiones de los agentes económicos que tienen influencia en el medio ambiente.

En el momento en que "los efectos no deseados son reversibles, el hábitat natural puede recuperarse total o parcialmente, de forma satisfactoria, siempre y cuando se lleven a cabo actuaciones de descontaminación y restauración de dicho hábitat, adquiriendo en este caso, gran importancia la planeación, el presupuesto y el control de los costos ambientales". (Pardavé, 2007, p.3)

Ahora bien, cuando los efectos no deseados son significativos, como por ejemplo con la contaminación, los costos derivados de la descontaminación, por muy elevados que sean, no permiten alcanzar una recuperación satisfactoria del entorno dañado. Así ocurre en actividades que suponen un riesgo grave para la supervivencia tanto del propio hombre como de algunas especies vegetales y animales. Este alto riesgo puede conducir a rechazar aquellas actividades que, por su elevado costo ecológico, no resultan en todo caso rentables dado que no existen ingresos capaces de compensar dicho costo. (Pardavé, 2007, p.3)

"Las acciones públicas en el tema de regulación se pueden clasificar como: i) de carácter planificador y ii) de carácter operativo. En Colombia, las primeras se mencionan en el documento Visión Colombia II Centenario: 2019, el Plan Nacional de Desarrollo y las Políticas de carácter sectorial. Las segundas consisten en todas aquellas herramientas operativas tanto de regulación (comando y control) como económicas, que incentivan el cambio en el comportamiento de los agentes económicos ${ }^{1}$, hacia el mejoramiento del medio ambiente2". (DANE, 2011, p.19)

En el capítulo 2 de la Guía para Decisores que realiza Delacámara por iniciativa de la CEPAL, se realiza una reflexión sobre la necesidad de cuantificar y contabilizar debidamente las pérdidas (o ganancias) en el bienestar de la sociedad, y como anexo en esta guía, se puede apreciar, cómo se realiza el análisis económico de externalidades a partir de la contaminación atmosférica asociada al transporte rodado urbano. (Delacámara, 2011, p.81)

\section{¿Cuáles son las externalidades ambientales?}

De forma general, las externalidades ambientales pueden ser positivas 0 negativas:

Una externalidad positiva puede darse entre dos formas de producción, en las que la producción de uno se beneficie con la del otro y viceversa.

Una externalidad negativa, por el contrario, es un efecto perjudicial para quien lo recibe, en la cual la forma de producción de uno perjudica a otra forma de producción o la convivencia de otro.

Según (Vásquez et al, 2008, p.2) Algunas externalidades ambientales negativas reconocidas a raíz de investigaciones y evaluaciones ambientales realizadas del crecimiento espacial de las ciudades chilenas, llevadas a cabo en las ciudades de Santiago, Valparaíso y Concepción, así como también en las ciudades intermedias

1 Algunos ejemplos pueden ser el Decreto 755 de 2003, que exime de renta la producción de energía eléctrica por energía eólica, biomasa y residuos agrícolas; y el Conpes3527 "política nacional de competitividad y productividad".

2 Entre las herramientas operativas de la gestión ambiental se encuentran las tasas retributivas y las tasas cobradas por el uso de los recursos naturales. 
de Quilloa, Chillán, Los Ángeles y Temuco, y sus efectos en el territorio, la ciudad y sus habitantes son:

- Cambios de los climas urbanos y pérdida de la calidad del aire como consecuencia de la incontrolada emisión de contaminantes atmosféricos, generación y fortalecimiento de islas de calor urbanas, disminución y hasta desaparición de las islas frías. (Peña y Romero, 2005; Romero y Sarricolea, 2006; Sarricolea y Romero, 2006)

- Desaparición, reducción y deterioro de las cubiertas vegetales, incluyendo terrenos de cultivo, áreas naturales y humedales (Romero y Fuentes, 2007; Romero y López, 2007; Smith, 2007).

- Pérdida de servicios ambientales y de la calidad de los paisajes naturales al interior y alrededor de las ciudades (Vásquez y Romero, 2007).

- Pérdida de la biodiversidad y reducción y desaparecimiento de hábitats, corredores y parches de vida silvestres (Romero y López, 2007).

- Generación y aumento de los índices de segregación socio ambientales al interior de las ciudades (Vásquez y Romero, 2007).

- Falta de justicia ambiental y concentración de los efectos adversos - incluyendo enfermedades relacionadas con el medio ambiente urbano - en forma discriminada sobre los sectores sociales más vulnerables (Romero y Molina, 2007; Vásquez y Romero, 2007) otras externalidades ambientales.

- Falta de actividades de saneamiento ambiental; hacinamiento en las viviendas en relación con los hogares; degradación del paisaje que afecta la calidad escénica de los diversos ambientes de la ciudad.

\section{¿Cuáles son las externalidades ambientales ocasionadas por la urbanización?}

En el año 2000, la población mundial alcanzó los 6.100 millones de habitantes y está creciendo a un ritmo anual de $1,2 \%$, 077 millones de personas al año. Para 2030, se espera que el $85 \%$ de la población mundial este en los países en desarrollo, con un 15\% en países menos desarrollados. Las ciudades están creciendo muy rápido - más del $90 \%$ del crecimiento poblacional en países en desarrollo tiene lugar en las ciudades y de éste se estima que el $60 \%$ de la población mundial viva en áreas urbanas. (Banco Mundial).

La mitad de la población mundial (3.500 millones de habitantes, aproximadamente) vive hoy en las ciudades, y se espera que antes del año 2050 dos tercios de la población vivan en zonas urbanas (8.500 millones de habitantes, aproximadamente). Esto agrava los dos problemas más acuciantes del mundo actual presentes en las ciudades, como son: la pobreza y la degradación del medio ambiente.

El crecimiento intensivo y extensivo de las ciudades genera más pobreza y minimiza los esfuerzos que los gobiernos locales ofrecen en el mejoramiento de los servicios a todas las personas. Además, la insuficiente disponibilidad de agua, la generación de residuos y el alto consumo energético se multiplican por la creciente población y las demandas de los entornos urbanos. El consumo concentrado de energía aumenta la contaminación del aire y la generación de grandes volúmenes de residuos y su mal tratamiento suponen múltiples riesgos para la salud humana.

Se ha podido conocer que el desarrollo urbano puede magnificar el riesgo de desastres medioambientales, como las inundaciones súbitas; las emisiones de los vehículos producen elevados niveles de plomo en el aire urbano; la contaminación y las barreras físicas que impiden el crecimiento de las raíces, fomentan la pérdida de masa forestal urbana; la fauna se ve perjudicada por sustancias tóxicas, pérdida del hábitat y las fuentes de alimentos.

La urbanización desmedida trae consigo un déficit de vivienda adecuada para la habitabilidad y el deterioro de estas por improvisación en su construcción y ocupación en zonas de retiro de quebradas y zonas de alto riesgo, desarticulación e improvisación de las acciones gubernamentales y en general falta de legalización y regularización 
de predios y viviendas en la mayor parte de algunos territorios.

Se observa también una prominente invasión del espacio público por negocios informales lo que acarrea inseguridad y la proliferación de animales callejeros y plagas.

Por otro lado, la sustitución de las áreas naturales y vegetadas por áreas urbanizadas implica disminuir la evaporación y la evapotranspiración y con ello desecar la atmósfera de las ciudades en varios porcentajes inferiores respecto a las áreas rurales. La construcción de edificios por otra parte, aumenta los efectos contención y/o fricción que frenan el viento y perturban su distribución antes, sobre y después de que los flujos de aire arriban a la ciudad.

La pérdida de áreas verdes significa que las funciones de reciclaje y limpieza del aire por parte de la vegetación a través del follaje por ejemplo, se vean limitadas, lo cual deriva en un aumento de la contaminación atmosférica. El sellamiento de los suelos por calles pavimentadas, techos, parqueaderos y centros comerciales, por su parte, disminuye absolutamente la infiltración de las aguas Iluvias en el suelo y facilita consecuentemente su escurrimiento superficial.

Mientras más sean las externalidades ambientales negativas causadas por la urbanización sobre los medios ambientes naturales, serán más y mayores las necesidades de recursos naturales y energía provenientes de los sistemas de soporte de vida que se requieren para sustentar las ciudades.

\section{Externalidades ocasionadas por la urbanización en Medellín}

Se ha escogido a la ciudad de Medellín como contexto de estudio, para detectar en ella las externalidades ambientales negativas (Figura 1).

\section{Ubicación geográfica}

La ciudad de Medellín se encuentra enclavada en el centro geográfico del Valle de Aburrá, sobre la cordillera central de los Andes, ver figuras 1,2 y 3 . La ciudad

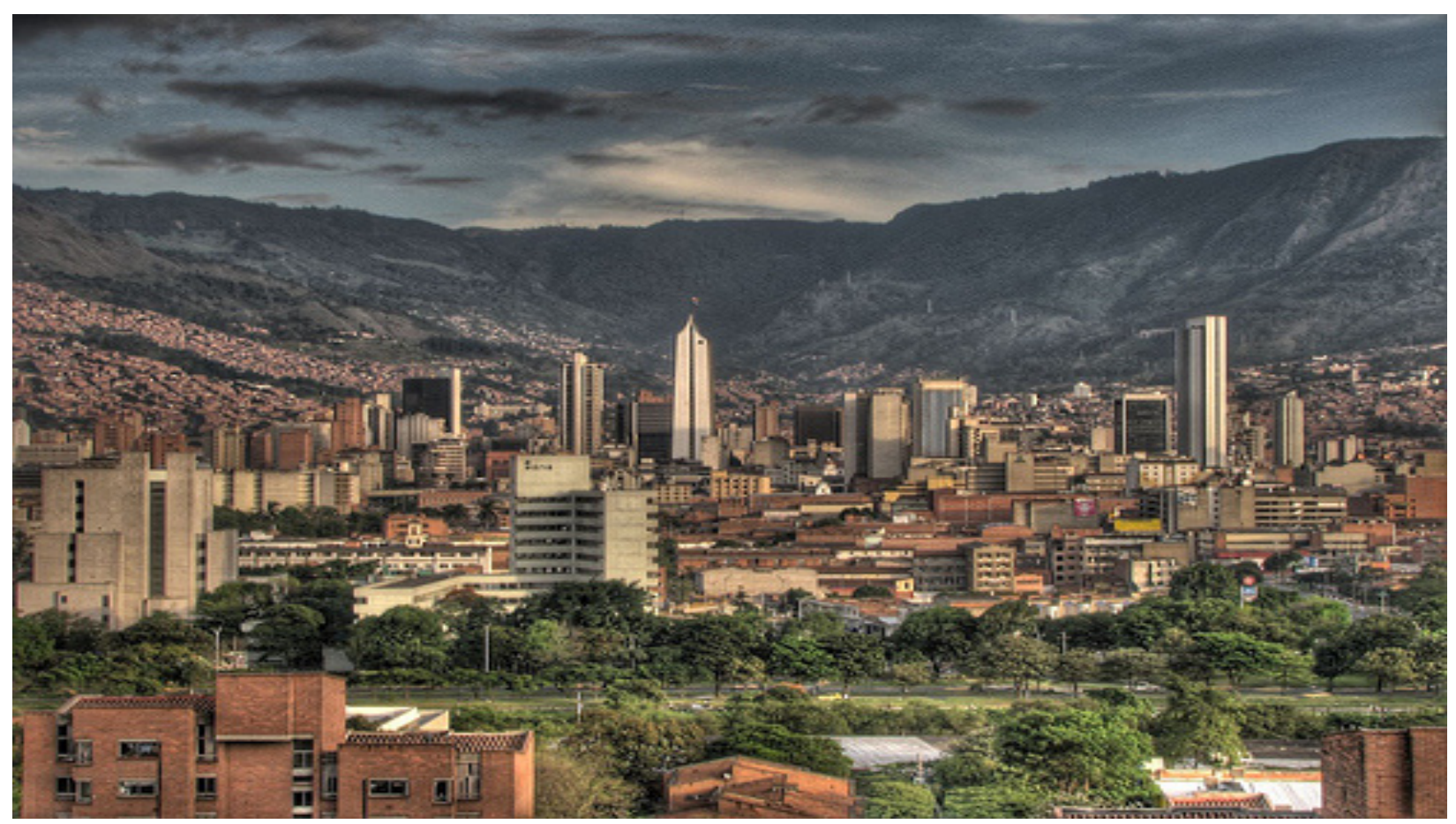

Figura 1. Ciudad de Medellín

Fuente: http://domingoenlamanana.com/medellin-se-prepara-para-su-segundo-delm/ 


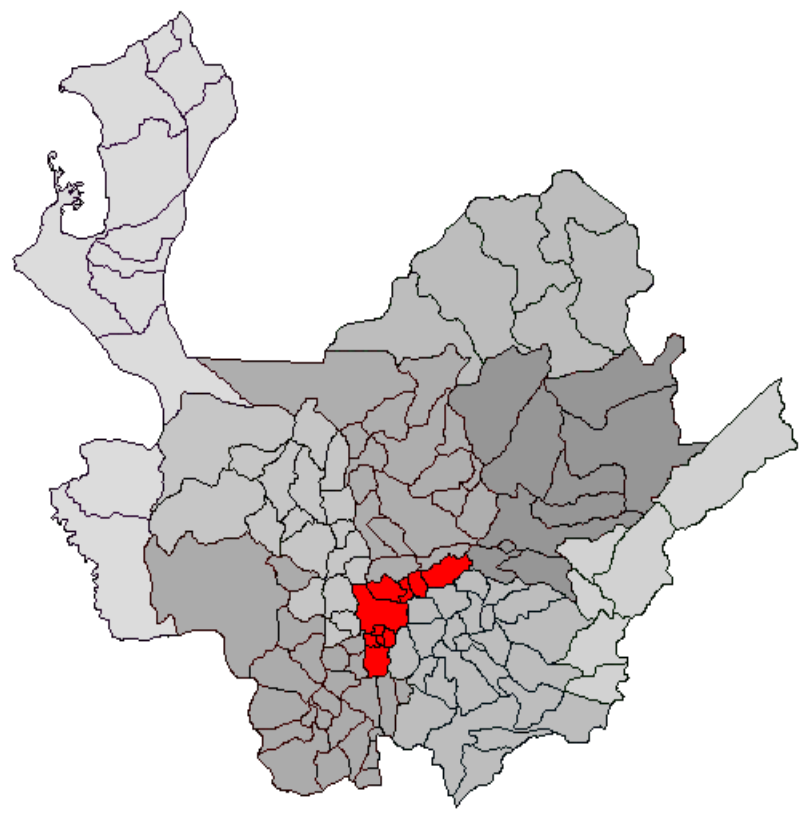

Figura 2. Antioquia y el Valle de Aburrá

Fuente:http://en.wikipedia.org/wiki/The_Metropolitan_Área_of_the_Aburr\%C3\%A1_Valley

cuenta con un área total de $380,64 \mathrm{~km}^{2}$ de los cuales $110,22 \mathrm{~km}^{2}$ son suelo urbano y $270,42 \mathrm{~km}^{2}$ son suelo rural, enmarcado por una topografía irregular y en pendiente, que oscila entre 1.300 y 2.800 metros sobre el nivel del mar, con numerosos lugares de gran valor paisajístico y ecológico (Figura 2).

\section{Morfología del Valle de Aburrá}

Es un valle estrecho y circundado por montañas, cruzado por un río y rodeado por quebradas que hacen parte de la cuenca del río Aburrá reconocido como río Medellín. Esta geografía ha determinado la imagen e identidad como la "Capital de la montaña" (Figura 3).

\section{Dinámicas de urbanización}

El área urbana de la ciudad de Medellín se divide en seis zonas divididas a su vez en comunas sumando un total de 16 comunas. Finalmente las comunas se dividen en barrios y en áreas institucionales. La ciudad de Medellín tiene un total de 249 barrios oficiales y 20 áreas institucionales. En la figura 4 se puede observar el mapa de la ciudad de Medellín con la división política de sus 16 comunas, clasificadas a su vez en sectores como son: las comunas, que

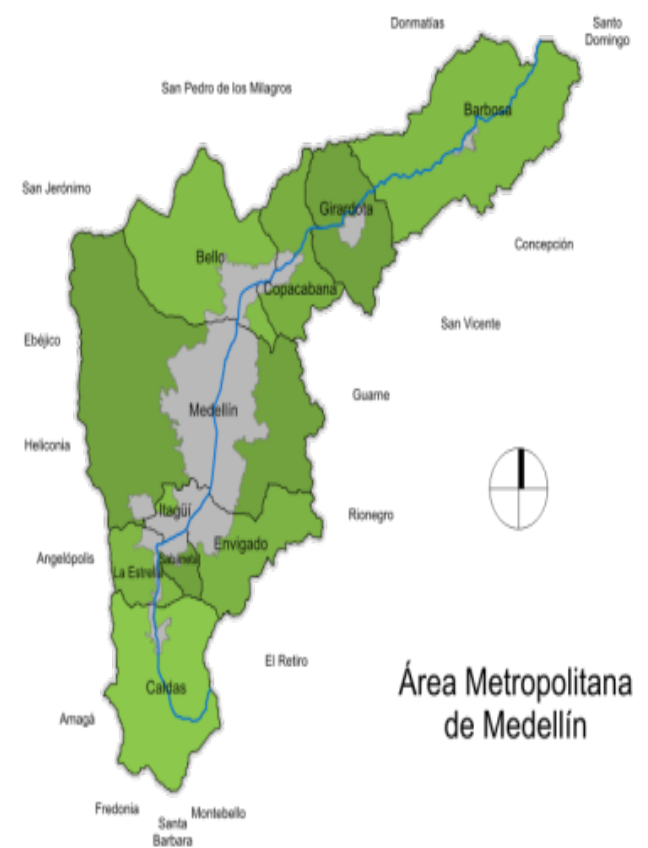

Figura 3. Valle de Aburrá y Medellín

Fuente:http://commons.wikimedia.org/wiki/File:Área_Metro_Medellin.svg

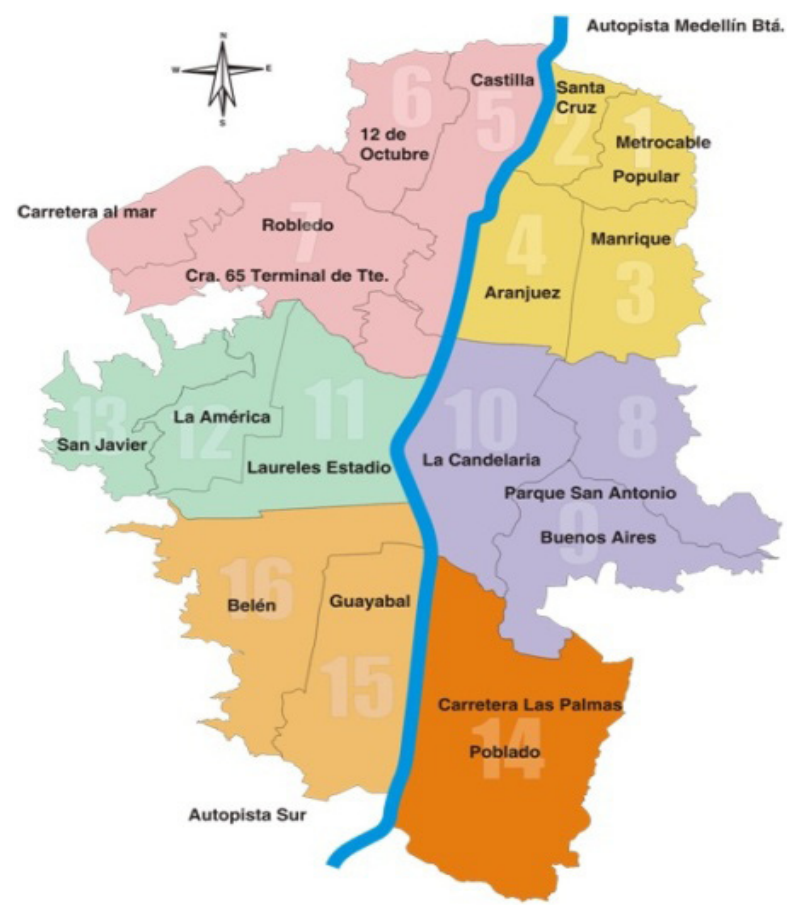

Figura 4. Comunas de Medellín Fuente: www.scielo.org.co

conforman el sector nororiental, el sector noroccidental, el sector centro oriente, centro occidente y los sectores suroriental y suroccidental, diferenciados en el mapa con colores diferentes para cada sector. 
Palmett, O. - Externalidades ambientales ocasionadas por la urbanización.

En la figura 5 se puede ver graficado el crecimiento poblacional ocurrido entre los años 1905 y 2012, destacándose que en la década de estudio (1990 a 2010) hay un crecimiento bastante significativo pasando de 1.630.009 habitantes en 1993 a 2.393.011 habitantes en el 2012, y pasando así a ser Medellín considerada la segunda ciudad más poblada de Colombia.

En la figura 6 se observa el mismo fenómeno de crecimiento poblacional expuesto en la gráfica de la figura 5, pero en este caso, representado en mapas que muestran de

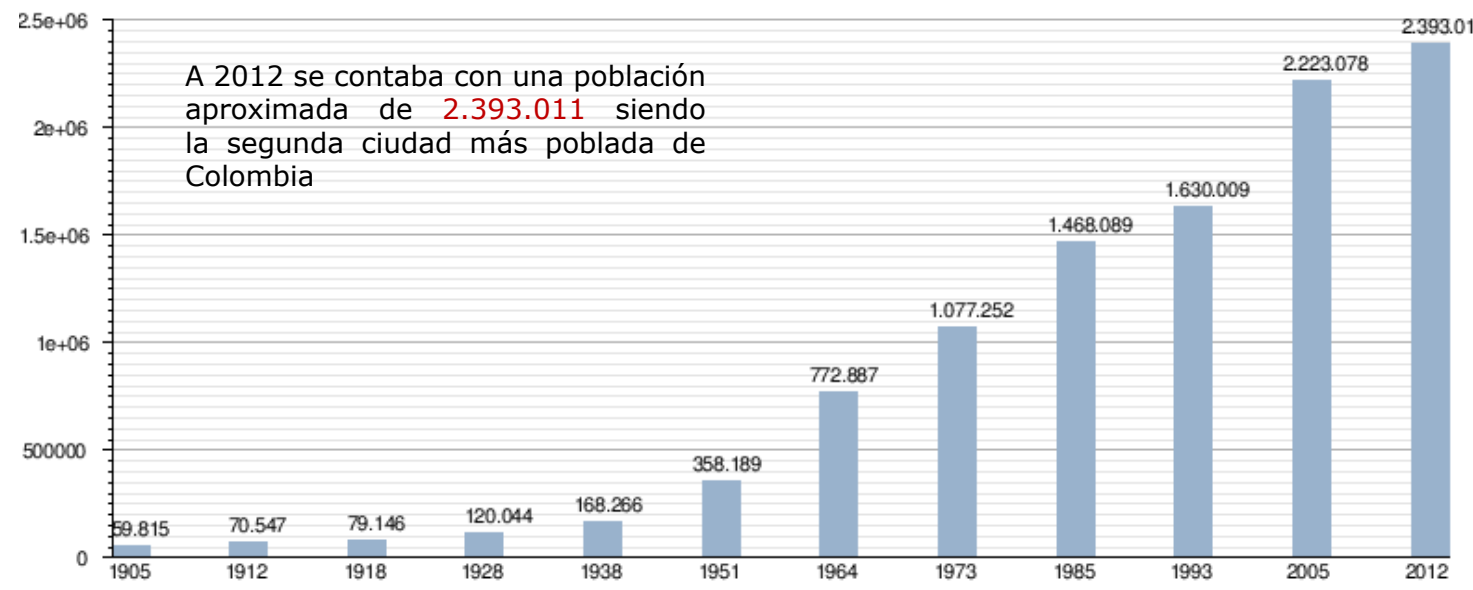

Figura 5. Población aproximada de Medellín por años

Fuente: http://wearethecityheroes.files.wordpress.com/2013/01/4evolucic3b3n.png

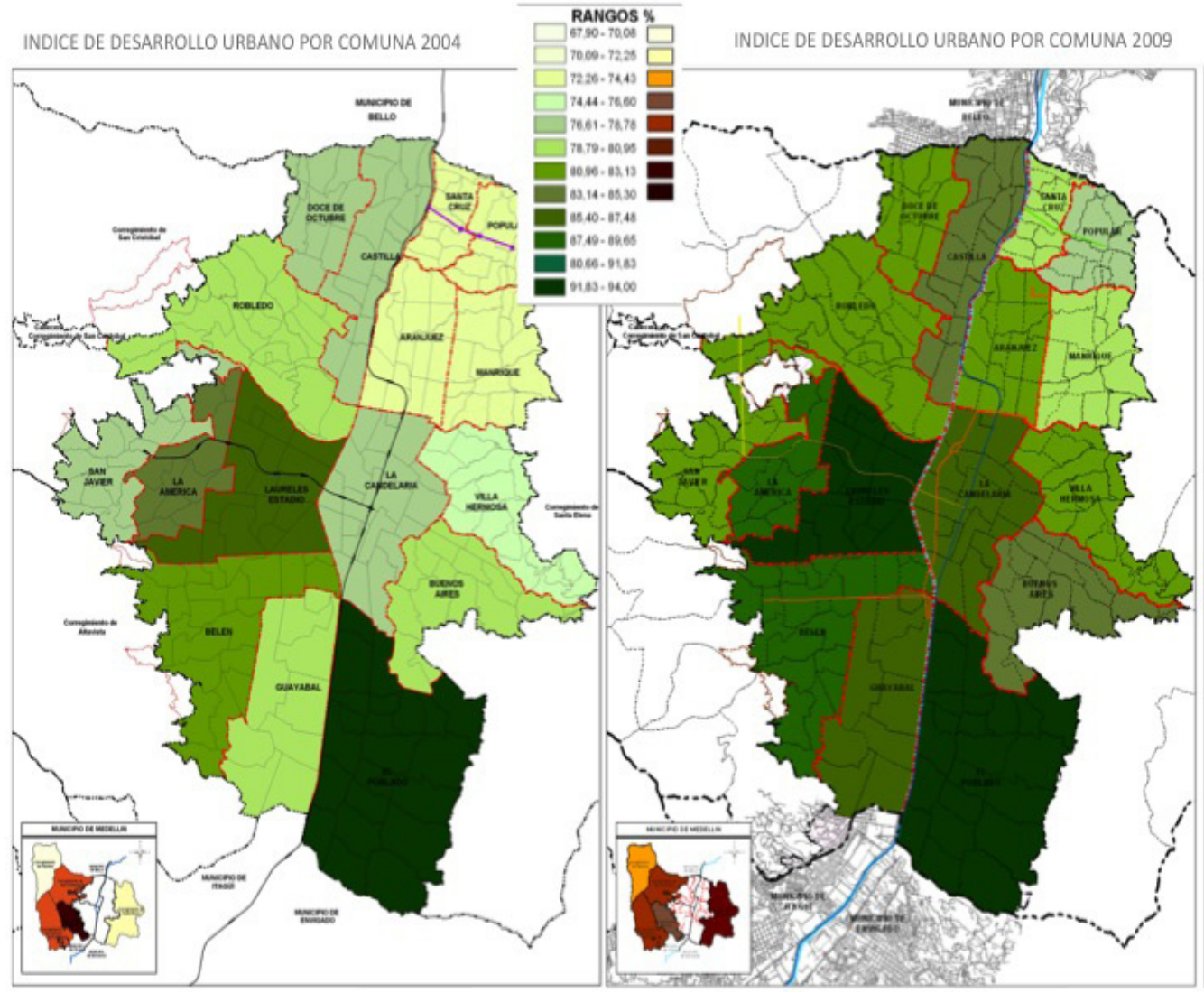

Figura 6. Índice de desarrollo urbano por comunas 2004 y 2009. Fuente: http://3.bp.blogspot.com/--vL2JxoyJd8/TtN4QSkkYOI/AAAAAAAAAZA/CnwZ6w04YSc/s1600/Slide11.jpg 
manera mucho más evidente el desarrollo urbano por comuna, ocurrido entre los años 2004 y 2009.

Por otra parte, es fuerte la dinámica que presenta Medellín en la población rural, una tendencia ascendente durante las últimas décadas de desplazamiento y reubicación, esto es debido a que la población de las áreas rurales se moviliza a zonas periféricas de la ciudad en busca de unas mejores condiciones de vida; esta ha sido una de las causas más grandes en la dinámica de urbanización en Medellín.

Además, no se pueden desconocer otros factores que inciden de forma directa como son la pobreza, la indigencia, el conflicto armado, el desempleo y la violencia como los principales promotores del desplazamiento. Esto suma como otra de las causas de las dinámicas de urbanización. Todo esto ha generado la creación de verdaderas colonias de desplazados en los barrios periféricos del municipio. Como se mapea en la figura 7.

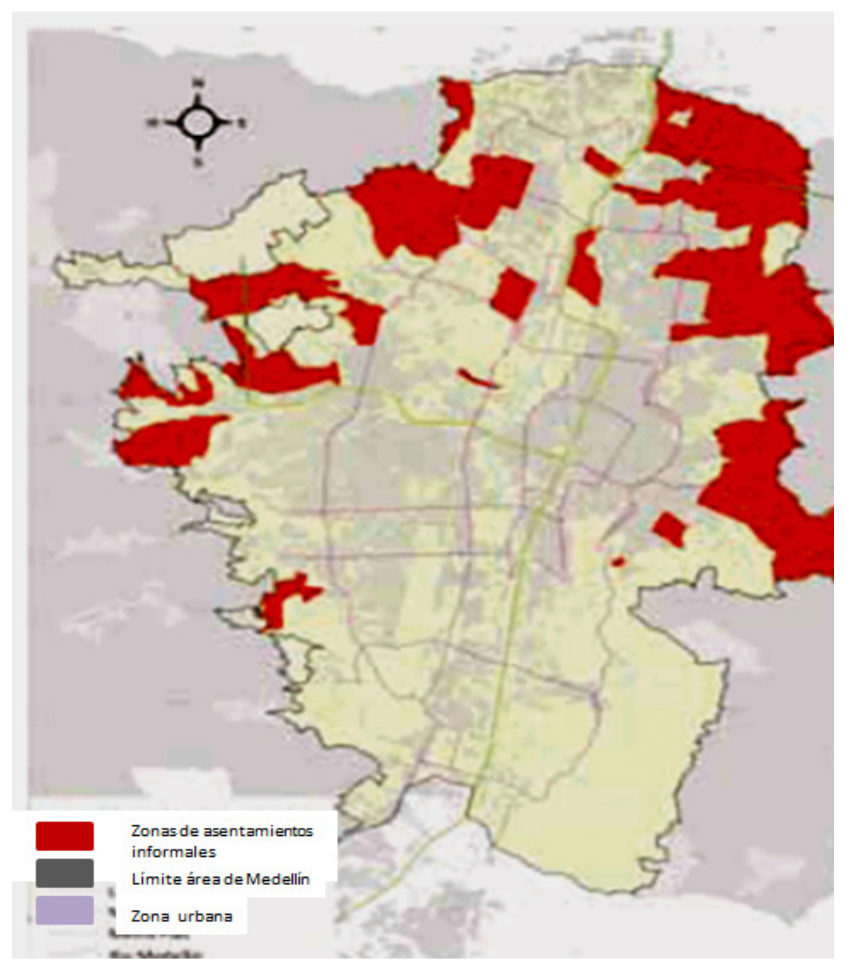

Figura 7. Zonas de asentamientos informales

Fuente: Dávila et al. (2006). www.scielo.unal.edu.co
La falta de claridad y el incumplimiento de la norma estipulada en el Acuerdo 46 de 2006 en cuanto al uso y clasificación del suelo, facilitó asentamientos en lugares inadecuados con poca habitabilidad, escasa seguridad y poco cubrimiento de servicios necesarios para la subsistencia y una buena calidad de vida (Figura 8).

Proliferan los asentamientos en las riberas del río, dando lugar a eventos de riesgo y vulnerabilidad en la población en época de lluvias y la atención de emergencias por desbordamiento de las quebradas, se hace cada vez más frecuente. Figura 9.

Una mirada general sobre la dinámica de urbanización en la ciudad de Medellín, se puede ver en las imágenes recopiladas en la figura 10 , en donde es clara la representación gráfica de la expansión y crecimiento de la ciudad.

Todo ello muestra como la dinámica de urbanización ha ido cubriendo el territorio cómo una mancha que ha ido creciendo, trayendo consigo una serie de problemáticas y deterioro ambiental, como ya se ha enunciado y que sin embargo se mostrará con una serie de evidencias precisas en el ítem a continuación.

\section{Externalidades ambientales negativas - evidencias}

La desigualdad en los recursos, las oportunidades y la calidad de vida, entre miembros de una misma población es un fenómeno que caracteriza a la mayoría de las sociedades contemporáneas que han padecido el incontrolado crecimiento humano y su urbanización, sin escapar de ello la ciudad de Medellín. Y su intensidad es tal que empapa la forma de vestir, los estilos de vida, y los espacios físicos.

Evidencias físicas en el paisaje de la forma en que la urbanización afecta a unos lugares más que a otros, como los ocurridos en los barrios Santa Cruz y El Poblado de Medellín. En contraposición, se observa cómo la imagen superior de la figura 11, correspondiente al barrio Santa Cruz, muestra una densidad mayor y una falta de vegetación notoria. Mientras que en la imagen inferior de la 
Palmett, O. - Externalidades ambientales ocasionadas por la urbanización.

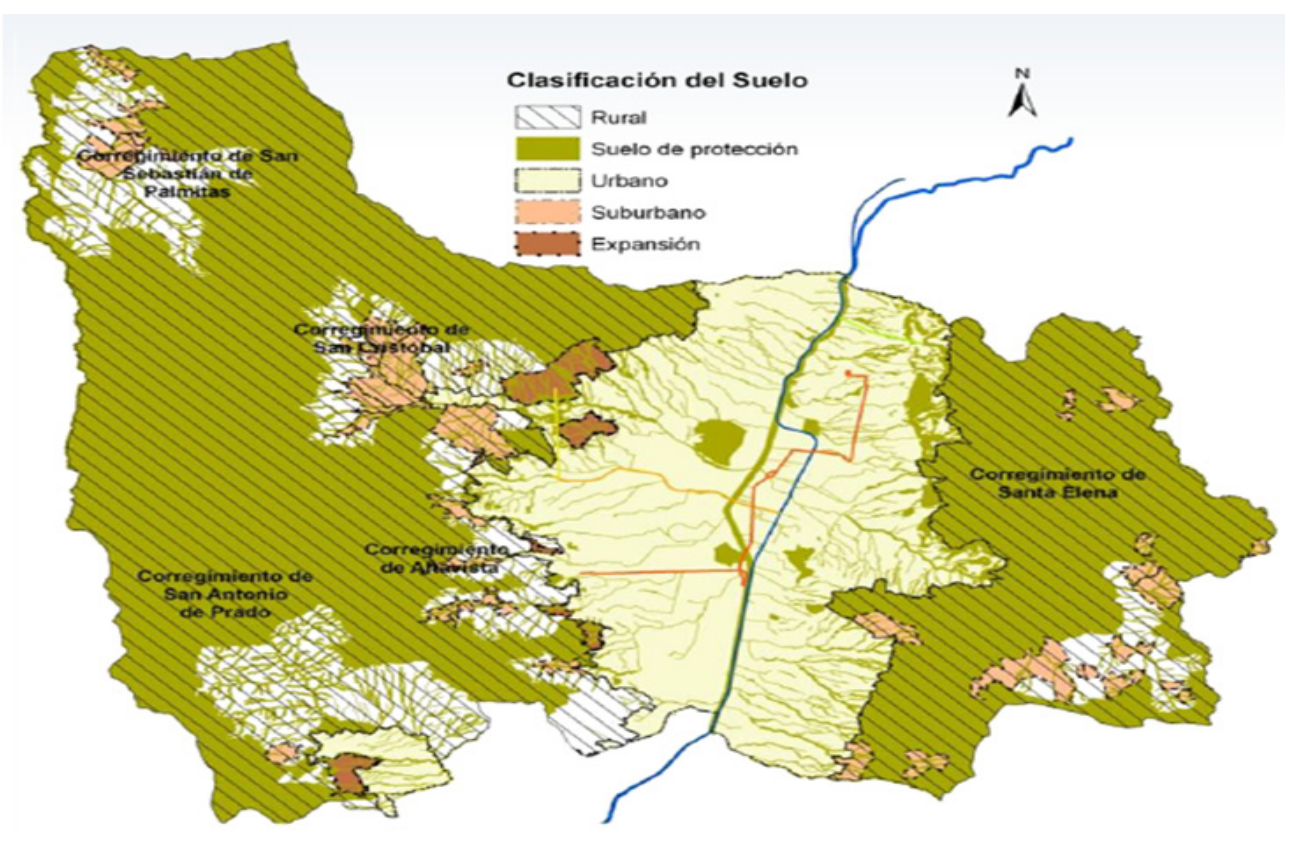

Figura 8. Clasificación del suelo

Fuente: Plan de ordenamiento territorial. Acuerdo 46 de 2006.

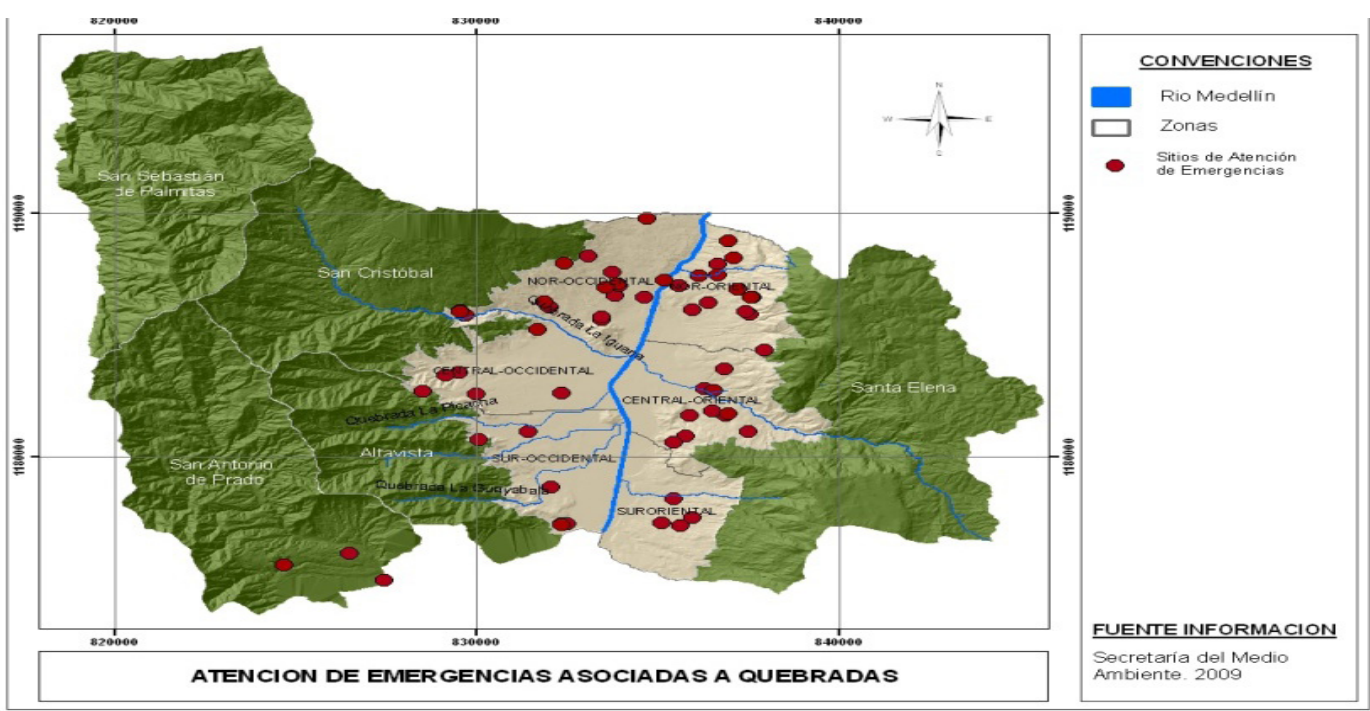

Figura 9. Atención de emergencias asociadas a quebradas

Fuente: www.medellin.gov.co

misma figura, correspondiente al barrio $\mathrm{El}$ Poblado, muestra mayor apertura del espacio y más componente verde como complemento. Barrio que ha mantenido en buen control a las externalidades ambientales, lo que ha establecido un buen equilibrio entre lo natural y antrópico.

La pobreza, la violencia, el desplazamiento, la marginalidad social, la movilidad, el desarraigo e inestabilidad son consecuencias aumentadas de la urbanización incontrolada, hechos que han generado sectores y barrios desestructurados e informales, como se muestra en la figura 12.

Entre 1980 y 1990, las densidades altas de pobladores asentados en las zonas planas y paralelas al río Medellín que estaban estables, comenzaron a disminuirse hacia los bordes del perímetro urbano. Esta dinámica diluyó lo que se denominaba la Ciudad Compacta y concentrada (Rueda, 1996) en las centralidades y dio lugar a otro tipo de ciudad; la ciudad difusa. 
Procesos Urbanos No 3 Enero - Diciembre; 2016
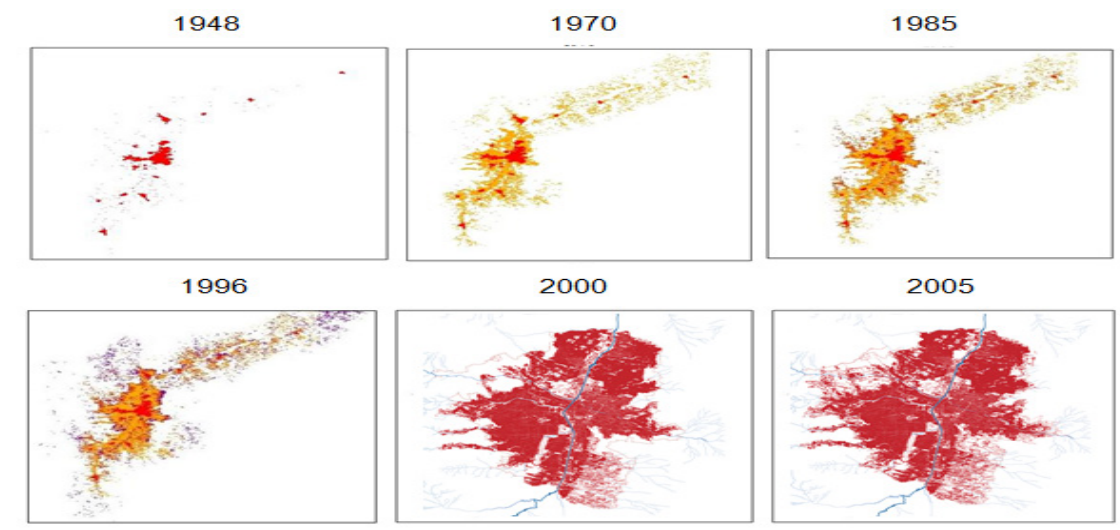

Figura 10. Proceso de ocupación de la mancha urbana en el Valle de Aburrá en la segunda mitad del siglo XX. Imágenes extraídas de la investigación Estudio de forma y el crecimiento urbano del Valle de Aburrá. UPB/AMVA, 2006.

Fuente: http://informalsettlements.blogspot.com/2011/03/spatial-conditions-of-violence-in-city.html

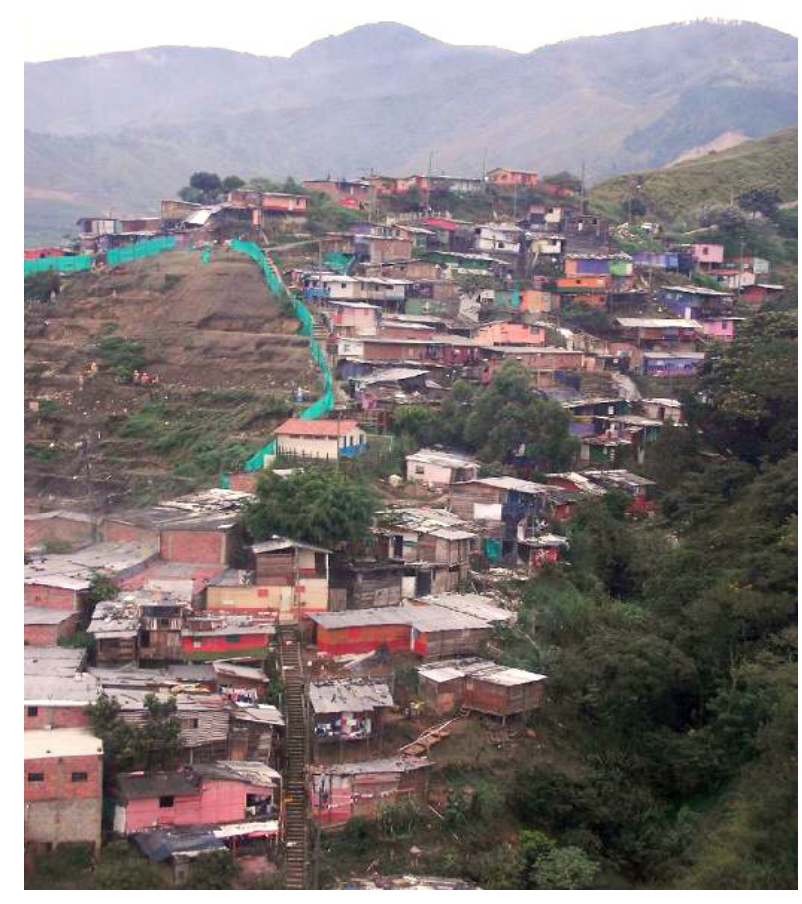

Figura 12. Movilidad, desarraigo, inestabilidad Fuente: http://bitacora.eafit.edu.co/?p=6786

Entre 1990 y 2000, las periferias de la ciudad crecieron por expansión urbanística aunque existieran condicionantes tan fuertes como la topografía en ladera, con una alta dificultad para generar infraestructura de servicios públicos y de accesibilidad. Fenómeno que dio lugar al tipo de Ciudad Difusa y extendida (Rueda, 1996), pero al mismo tiempo se diluían con ella los soportes de buena habitabilidad y calidad de vida enmarcados en la ciudad compacta.
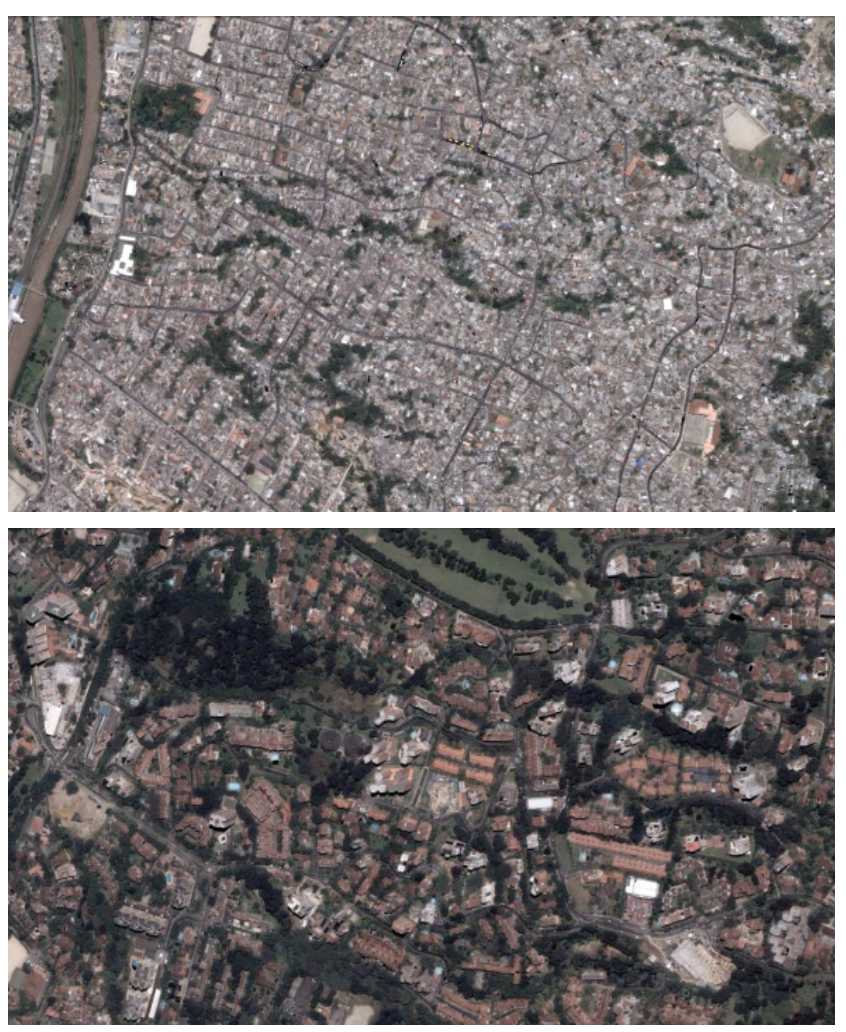

Figura 11. Arriba barrio Santa Cruz, comuna 2; Abajo barrio Poblado, comuna 14. Fuente: http://pijamasurf.com/2012/06/la-desigualdad-social-vistadesde-google-earth-barrio-rico-vs-barrio-pobre/

Todos estos cambios paulatinos fueron tema de estudio gubernamental debido al escaso control que se podía vislumbrar en las acciones emprendidas para aportar mejoramiento en los servicios urbanos y ambientales. Es así como entre los años 2000 y 2010, se promueve un crecimiento de la ciudad orientado hacia 
Palmett, O. - Externalidades ambientales ocasionadas por la urbanización.

adentro, con énfasis en las zonas centrales próximas al río Medellín, dotándolas de mejoras en la infraestructura, para acoger nuevos grupos humanos y abrir espacios de mejor convivencia para pobladores de la periferia que quisieran reasentarse.

Este cambio combinado en la dinámica urbanística Extensiva y Dispersa (Portas, 2003, p.227) en la reacomodación de la ciudad para hacer más visibles las acciones gubernamentales, hizo crear conciencia de las innumerables acciones que debían emprenderse para apoyar esta idea inicial que mostró buenos resultados.

Acciones que contrarrestan el efecto negativo de las externalidades ambientales ocasionadas por la urbanización en Medellín.

Las estrategias llevadas a cabo en Medellín para contrarrestar los efectos de las externalidades ambientales negativas, parten de un objetivo general: construir, re- construir y recuperar espacios públicos, con el fin de conseguir así una convivencia social y de seguridad en la ciudad. En la tabla 1 se recogen las acciones aplicadas que han permitido contrarrestar las externalidades ambientales en Medellín.

Con la política de crecimiento hacia adentro, se buscaba limitar en Medellín la expansión urbana hacia los bordes de las laderas con el fin de prevenir las situaciones de riesgo, en razón de las fuertes pendientes e inestabilidad geológica de los terrenos y evitar los mayores costos económicos y ambientales de la ciudad expandida.

En el año de 1990 hubo una presencia del Estado ante las externalidades ambientales negativas; es hasta el año 2004 cuando el gobierno hace su presencia de forma significativa y consciente ante esta problemática, como lo muestra la siguiente descripción que resume las acciones emprendidas a nivel gubernamental para aplicar correctivos a las externalidades ambientales.

Es la participación ciudadana, introducida por la constitución política de 1991, la que abre espacios para que la ciudadanía desarrolle iniciativas y contribuya con sus proyectos a la construcción de un Estado democrático. Es así como la temática ambiental considerada con especial atención por la Constitución de 1991, organiza su institucionalidad a partir de la Ley 99/93. Esto indica que, como línea base, la temática como su institucionalidad apenas comienza su formación en el país, en ese momento.

En la administración de 1992 a 1994, con la Ley 99 de 1993, que plantea cómo el desarrollo debe enmarcarse a la luz del concepto de desarrollo sostenible, asignándole funciones ambientales a los municipios; y de conformidad con la Ley 142 de 1994, en Medellín se conformaron 4 Comités de Desarrollo y Control Social de los Servicios Públicos Domiciliarios, se inicia en el

Tabla 1. Acciones de mejoramiento.

\section{ACCIONES}

\begin{tabular}{ll}
\hline SOCIALES & PARTICIPACIÓN DE LA CIUDADANÍA \\
INSTITUCIONALES & COMUNICACIÓN CONTINUA \\
& ENTRE LAS INSTITUCIONES \\
FÍSICAS & ENTRE LOS SECTORES \\
& EN EL ESPACIO PÚBLICO \\
& EN LOS LUGARES DE REUNIÓN SOCIAL \\
& EN LOS RECORRIDOS Y USOS URBANOS \\
& EN LA MOVILIDAD, CONECTIVIDAD Y EL TRANSPORTE \\
& EN LAS VÍAS Y CONEXIONES PARA EL DESPLAZAMIENTO \\
& MEJORAMIENTO HABITACIONAL DE LAS VIVIENDAS \\
& MEJORAMIENTO DEL MEDIO AMBIENTE \\
& MEJORAMIENTO DE LOS EQUIPAMIENTOS URBANOS \\
\hline
\end{tabular}

Fuente: elaboración propia. 
municipio un lento proceso de participación que ha venido ganando en calidad y cobertura, además de presentar nuevas formas que el ingenio abundante de los ciudadanos ha creado y se ha ido multiplicando correlativamente con el descenso en los actos de violencia social.

La línea de base ambiental para Medellín en 1994 muestra grandes limitaciones en el tratamiento que los Planes de Desarrollo le dan al tema, hasta el año 2000, sin una clara orientación ni conocimiento del problema. Para ese momento actúan en Medellín dos autoridades ambientales. En el área rural: la Corporación Autónoma Regional del Centro de Antioquia Corantioquia; y en el área urbana: El Área Metropolitana del Valle de Aburrá. Amva.

A estas dos autoridades ambientales les corresponde administrar los recursos naturales renovables a través de un conjunto de actuaciones jurídicas y técnicas, tanto para el otorgamiento de permisos, autorizaciones y licencias ambientales exigidos por la Ley para el uso, aprovechamiento y movilización de los mismos, como para regular el desarrollo de actividades que puedan afectar el medio ambiente. (Corantioquia, Medellín)

A nivel internacional en 1992 se promulgan los principios fundamentales de la Cumbre de Río de Janeiro, en la segunda Cumbre de la Tierra, en la cual han de estipularse 3 principios a los cuales Medellín les estaría apuntando años más adelante de forma rigurosa y juiciosa.

El principio 1: Los seres humanos constituyen el centro de las preocupaciones relacionadas con el desarrollo sostenible. Tienen derecho a una vida saludable y productiva en armonía con la naturaleza.

El principio 8: Para alcanzar el desarrollo sostenible y una mejor calidad de vida para todas las personas, los Estados deberían reducir y eliminar las modalidades de producción y consumo insostenibles.

El principio 26: Los Estados deberán resolver pacíficamente todas sus controversias sobre el medio ambiente por medios que corresponda, con arreglo a la Carta de las Naciones Unidas.

En la administración de 1995 a 1997, apenas se menciona el tema urbano-ambiental y lo trata sin conocimiento y sin énfasis particular, tal vez por tratarse de un tema novedoso y que gana importancia a través del tiempo. La importancia de la preservación ambiental y la búsqueda del desarrollo sostenible (según el informe Brundtland), como tema de discusión en todos los países y en particular en los más desarrollados, obliga a las administraciones a introducirlo gradualmente.

En el único aspecto que la participación de la comunidad presenta algún avance en este período, más formal que real, fue en la prestación de los Servicios Públicos, requerida por la Ley 142 de servicios públicos. Y en 1996 se instala el PRIMED Programa Integral de Mejoramiento de barrios subnormales.

En la administración de 1998 a 2000, el tema del medio ambiente y los recursos naturales apenas se introduce y en forma caótica, sin perspectivas y atendiendo acciones puntuales que carecen de una formulación establecida sobre un diagnóstico que evalúe su estado. Se promulga la Ley 388 de 1997 que cuenta con un marco estructurado que permite a las administraciones municipales hacer ordenamiento territorial.

En la administración de 2001 a 2003, se introduce el tema ambiental con una mayor coherencia y haciendo referencia a temas concretos. Esta administración recibió un agudo problema de manejo de residuos sólidos, dado el agotamiento de la vida útil del relleno sanitario de la Curva de Rodas y el creciente conflicto ambiental planteado por las comunidades vecinas al relleno, que venían exigiendo de tiempo atrás su cierre. En esta administración se toma la decisión de cerrarlo.

Es por esto que el Ministerio de Medio Ambiente (actualmente Ministerio de Ambiente, Vivienda y Desarrollo Territorial), por medio de la aprobación del Consejo Nacional Ambiental, desarrolló en el año 2002 los Lineamientos Ambientales para la Gestión Urbano Regional en Colombia, donde se plantean conceptos, criterios y directrices generales en materia ambiental que deben seguir las instituciones y los actores sociales comprometidos con la gestión de los centros urbanos y sus entornos regionales; propuesta que no limita la acción 
Palmett, O. - Externalidades ambientales ocasionadas por la urbanización.

de la gestión urbana exclusivamente al interior de las ciudades, sino que plantea un enfoque regional para actuar sobre los municipios.

En la administración de 2004 a 2007, primer plan de desarrollo de cuatro años de duración. En el año 2004, Medellín cuenta con un diagnóstico ambiental y está en proceso el SIGAM (Sistema de Información para la Gestión Ambiental), que indica que existen en la ciudad problemas de contaminación como altos niveles de ruido y deterioro de la calidad del aire.

"La administración de 2004 identifica en su diagnóstico inicial los siguientes elementos: El crecimiento de la ciudad se ha dado, en muchos casos, a expensas de la destrucción de áreas de protección y reservas naturales, lo cual genera deterioro y fragmentación de los ecosistemas y amenaza la biodiversidad, las fuentes de agua y los demás servicios ambientales que prestan». (Alcaldía de Medellín, 2006, p.39).

Al finalizar 2007 se encuentra en funcionamiento el SIGAM y la Secretaría del Medio Ambiente fortalecida, lo que permite a la ciudad y a la próxima administración un manejo más eficiente y eficaz del medio ambiente y las externalidades ambientales negativas.

El SIGAM, Sistema de Gestión Ambiental de Medellín, está orientado a la articulación y desarrollo de instrumentos técnicos y metodológicos, jurídicos y normativos, económicos y financieros, administrativos y operativos, de participación y concertación, para articular los procesos de gestión ambiental en el municipio de Medellín. (Alcaldía de Medellín, 2006. p.1).

El PAM, Plan Ambiental de Medellín 2007 a 2019, define las directrices, estrategias, programas y proyectos a mediano y largo plazo tendientes al ordenamiento, manejo y gestión de los recursos naturales y ambientales, para mejorar la calidad ambiental y contribuir al desarrollo sostenible. (Alcaldía de Medellín, 2006, p.1)

Además de los instrumentos definidos en el SIGAM y el PAM, el componente de participación es fundamental; a través de él se involucran todos los ciudadanos y los sectores gubernamental y privado, mediante mecanismos y procesos educativos, culturales y sociales que buscan la gestión y la concertación.

En la administración de 2008 a 2011, comienza a funcionar El Sistema de Información Ambiental de Medellín - SIAMED - que integra la generación, producción, normalización, análisis y consulta de información de los proyectos ambientales del municipio de Medellín y entidades que intervienen los recursos naturales en el territorio, soportado por una base de datos centralizada y un entorno de consulta y administración vía Web, integrado a SAP y al visor geográfico corporativo Mapas Medellín, el cual utiliza la plataforma de ArcGIS. Su principal objetivo es facilitar el acceso oportuno a la información ambiental, convirtiéndose en un instrumento estratégico para la toma de decisiones en los diferentes escenarios que involucran al medio ambiente y sobre todo, garantizando el libre derecho que tiene la comunidad de acceder a fuentes de información pública.

\section{CONCLUSIONES Y RECOMENDACIONES}

Por lo expuesto anteriormente, se evidencia que, la problemática ambiental no solo es reflejo de procesos industriales o de consumo, también lo es por la urbanización y/o construcción, especialmente de viviendas no planeadas, ni legalizadas, habitadas generalmente por la población más pobre del país, generando con ello las externalidades ambientales negativas.

Las externalidades ambientales han existido y seguirán existiendo, pero el conocimiento de sus afecciones al ser humano y al medio ambiente han hecho que se tomen medidas fuertes para contrarrestar, evitar y controlar sus efectos, como por ejemplo, la imperiosa necesidad en el tratamiento que debe darse a las aguas servidas, toda vez que estas disminuyen el valor de una ciudad, de un país; puesto que no solo degradan el suelo, sino que son promotoras de enfermedades entero parasitarías, lo que sustenta aún más la necesidad de inversión pública y privada en este tipo de proyectos.

Por otro lado, y para el caso que se toca, las

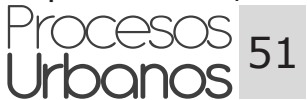




\section{Procesos Urbanos N³ Enero - Diciembre; 2016}

empresas constructoras deberían implementar medidas estratégicas que evalúen los efectos sociales, tecnológico- culturales, económicos y ecológicos, que permitan crear una cultura ambiental, ya que los proyectos arquitectónicos y/o constructivos no deben sustentarse solo en los beneficios económicos, a expensas del medio ambiente. Así como las empresas establecen un costo social en sus transacciones, deberían comenzar a considerar un costo ambiental, en el que las actividades sean en pro del medio ambiente e incluso complementarias, que alcancen beneficios favorables para toda la sociedad, pero indudablemente en pro de los actores más vulnerables, como la población más pobre, y entre ellos, los menores de edad.

Es indiscutible que las evidencias en la aplicación de acciones y estrategias de alivio, muestran el gran avance que ha habido en materia de manejo, control y mejoras en el tema de medio ambiente, relacionado con las externalidades ambientales ocasionadas por la urbanización en la ciudad de Medellín, sobre todo la creación de organismos que se encargan de crear leyes, normas y programas para velar por el cumplimiento de las mismas. Organismos que no desconocen el avance que se ha realizado en otros países con los mismos problemas o dificultades y que se enmarcan en los propósitos que a nivel mundial se han venido difundiendo por centros mundiales al cuidado del medio ambiente y la calidad de vida del hombre. Sin embargo, considerando que esta problemática no solo es de interés de los pueblos de América Latina, la expresión de preocupación mundial más destacada se encuentra en la firma del Protocolo de Kioto. El Protocolo de Kioto es un Acuerdo que entró en vigencia el 16 de febrero de 2005, ratificado por 166 países que buscan reducir en cuatro años (2008-2012), un 5.2\% de las emisiones de gases efecto invernadero globales y minimizar así el efecto en el cambio climático y deterioro ambiental.

Se trata entonces es de determinar niveles permisibles de deterioro de los recursos y del medio ambiente, que permitan internalizar las llamadas externalidades negativas, proponiéndose metas para alcanzar el objetivo de contrarrestar el efecto negativo causado en estos procesos; esta debería hacerse en forma tal que requiriera una mínima interferencia externa al mercado. Internalizar equivale a asumir el costo del deterioro causado, considerando que el que contamine, debería ser el que pague.

Medellín ha sido una ciudad que ha sabido aprovechar sus puntos débiles para volverlos fortalezas en el manejo de las externalidades, y esto ha hecho que soluciones que se han pensado para un correctivo en la planeación urbana, también sirvan y se apliquen para problemáticas sociales y culturales, mejorando no solo el aspecto visual del entorno urbano, sino la convivencia, la seguridad y la calidad de vida de sus habitantes.

Las autoridades competentes que no desconocen el problema del deterioro ambiental causadas en buena parte por las externalidades negativas vía producción, construcciones y/o urbanización, consumo, entre otras, han actuado para encontrar los correctivos necesarios. El ente rector de la política ambiental en Medellín es el SIGAM, Sistema de Gestión Ambiental de Medellín y la Secretaría del Medio Ambiente que conjunto al PAM, Plan Ambiental de Medellín 2007 a 2019, articulados al POT, Plan de Ordenamiento Territorial, han adelantado acciones tendientes al mejoramiento de la calidad de vida de los ciudadanos, conservando y protegiendo el patrimonio ambiental, al ejercer control, seguimiento y monitoreo sobre el manejo de los recursos naturales y los usos del suelo en la ciudad de Medellín, lo que ha permitido con esto, establecer parámetros de control en la expansión urbana.

No es un trabajo terminado, es apenas un comienzo que ha emprendido la ciudad de Medellín, al igual que otras ciudades latinoamericanas, pero es un trabajo a largo plazo al cual hay que darle tiempo para que la cultura se impregne, se transforme y con ello, cambie para bien, nuestro entorno. 
Palmett, O. - Externalidades ambientales ocasionadas por la urbanización.

\section{REFERENCIAS}

Aguilera Klink, F.; Alcántara, V. (2011): De la economía ambiental a la economía ecológica. Editorial CIP-Ecosocial. Barcelona, pág. 252.

Alcaldía de Medellín. Medellín y su población. Documento técnico de soporte POT [acuerdo 46/2006] municipio de Medellín.

Alcaldía de Medellín. Secretaría de Medio Ambiente. (2006). Política Ambiental de Medellín. Por una sociedad sostenible para futuras generaciones. Medellín, Colombia. Sitio Web: http:// www.medellin.gov.co/irj/go/km/docs/wpccontent/Sites/Subportal\%20del\%20Ciudadano/ Medio\%20Ambiente/Secciones/Informaci\%C3\%B3n\%20General/Documentos/2010/ PoliticaAmbientalDeMedellin/intro.html

Banco Mundial. "Informe sobre el desarrollo mundial»1995, 1996, 1997, 1998, 1999 у 2000. Sitio principal sobre desarrollo urbano del Banco Mundial. http://www.bancomundial.org/ temas/cities/datos.htm

Castro, R. Mokate, K. (1998). Evaluación económica y social de proyectos de inversión, Editorial Alfaomega. Bogotá: Universidad de Los Andes. Consultado en la dirección web: https://es.scribd.com/doc/259435026/Evaluacion-Economica-y-Social-de-Proyectos-deInversion.

Corantioquia Medellín. (online). Citado en noviembre 3 de 2006. en: http://www.corantioquia/> Dane. Departamento Administrativo Nacional de Estadística. (2010): Indicadores básicos. Consultado en la dirección web: www.dane.gov.co

Declaración de Río sobre el Medio Ambiente y el Desarrollo. (1992): Conferencia de las Naciones Unidades sobre el Medio Ambiente y el Desarrollo. Consultado en la dirección web: http://www.bioculturaldiversity.net/Downloads/Papers/Rio_declaration_Spanish.pdf

Delacámara, G. (2008). Análisis económico de externalidades ambientales. Guía para decisores. Documento de proyecto. German Agency for Technical Cooperation - NU. CEPAL. Repositorio Digital CEPAL. Biblioteca CEPAL. 82 págs. Consultado en la dirección web: http://repositorio.cepal.org/bitstream/handle/11362/3624/S2008426_es.pdf?sequence=1

Concejo de Medellín. (2006): El Plan de Ordenamiento Territorial (P.O.T.) de Medellín. Acuerdo Municipal no 46 de 2006, por el cual se revisa y ajusta el Plan de Ordenamiento Territorial (POT) para el municipio de Medellín y se dictan otras disposiciones según la Ley 388 de 1997 y los decretos nacionales 879 de 1998 y 4002 de 2004; en los cuales se adopta el contenido de la revisión y ajuste al Plan de Ordenamiento Territorial (Acuerdo 62 de 1999) y sus normas complementarias.

Ministerio de Ambiente, Vivienda y Desarrollo Territorial. (2009): Vivienda y hábitat en Medellín. Compes 3305 de 2004. Lineamientos para optimizar la política de desarrollo urbano. Presentación de 20 diapositivas.

Nicholson, W. (2008). Teoría microeconómica. Principios básicos y ampliaciones, 9a ed., por Cengage Learning Editores, S.A. México, D.F, Consultado en la dirección web: https://www.academia.edu/8459394/Teor\%C3\%ADa_microecon\%C3\%B3mica_ Principios_b\%C3\%A1sicos_y_ampliaciones_9ed_-_w.nicholson.

Pardavé L., W. 2007. Estrategias Ambientales de las 3R a las 10R. Eco Ediciones Itda. Bogotá. $92 \mathrm{P}$.

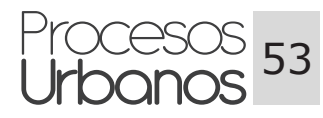


Portas, N. (2003). De una ciudad a otra: perspectivas periféricas. En: Martín Ramos, Ángel. (2004). Lo urbano en 20 autores contemporáneos. Publicado por Universitat Politécnica de Catalunya. Iniciativa Digital Politécnica. Consultado en la dirección web: https://books. google.com.co/books? id=UkJpBgAAQBAJ\&printsec=copyright\&hl=es\&source=gbs_pub_ info_r\#v=onepage\&q\&f=false

Rocha C., L.; Pinzón H, L.; Usaquén C, M. (2007). Limitaciones de los derechos de propiedad privada en el área urbana de Bogotá: una perspectiva neo institucional, en Revista Cife, Universidad Santo Tomás, p.155-181. Consultado en la versión web:

http://www.usta.edu.co/otras_pag/revistas/r_cife/cife12/RC12_10.pdf

Rueda, S. (1996). La ciudad compacta y diversa frente a la conurbación difusa. En primer catálogo español de buenas prácticas (Madrid: Ministerio de Obras Públicas, Transportes y Medio Ambiente, 1996) Tomado de La construcción de la ciudad sostenible .http://habitat. aq.upm.es/cs/p2/a009.html

Schnitter, P.; Giraldo, M.; Patiño, J. (2006): la ocupación del territorio en el proceso de urbanización del área metropolitana del Valle de Aburrá, Colombia. Publicado en la Scripta Nova. Revista electrónica de geografía y ciencias sociales. Barcelona: Universidad de Barcelona, vol. X, núm. 218 (83), 1 de agosto de 2006. Consultado en la dirección web. http://www.ub.es/geocrit/sn/sn-218-83.htm. [ISSN: 1138-9788]

Stiglitz, J. (2000). La economía del sector público, 3a ed., España, Antoni Bosch. Consultado en la dirección web: https://finanzaspublicasuca.files.wordpress.com/2011/10/economiadel-sector-publico-stiglitz.pdf

Torres Arzayús, P.; García Botero, M. (2010): Ciudades del mañana. Gestión del suelo urbano en Colombia. Banco Interamericano de Desarrollo BID. Washington, D.C., págs. 295

UN. Declaración de Río sobre medio ambiente y desarrollo. Dirección web: http://www.un.org/ spanish/esa/sustdev/agenda21/riodeclaration.htm

Vásquez, A. E., Romero, H., Fuentes, C., López, C. y Sandoval, G. (2008). Evaluación y simulación de los efectos ambientales del crecimiento urbano observado y propuesto en Santiago de Chile. Actas del Congreso Nacional de Desarrollo Rural. Santiago de Chile. Consultado en la dirección web: http://repositorio.uchile.cl/bitstream/handle/2250/118149/ EVALUACION_Y_SIMULACION_DE_LOS_EFECTOS_AMBIENTALES_DEL_CRECIMIENTO_ URBANO_OBSERVADO_Y_PROPUESTO_EN_SANTIAGO_DE_CHILE.pdf? sequence $=1$ 